UITED STATES

RTMENT OF

MMERCE

BLICATION

$\cos$ os

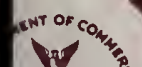

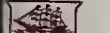

National Bureay of Standarts

Library, $[$ ? $\quad \therefore$ ildg.

AUG 181970

NBS TECHNICAL NOTE 521

\title{
Present State of the Classical Theory of Quantitative Electron Probe Microanalysis
}

U.S. PARTMENT OF OMMERCE National

Bureau of

Standard's 


\section{NATIONAL BUREAU OF STANDARDS}

The National Bureau of Standards ' was established by an act of Congress March 3, 1901. Today, in addition to serving as the Nation's central measurement laboratory, the Bureau is a principal focal point in the Federal Government for assuring maximum application of the physical and engineering sciences to the advancement of technology in industry and commerce. To this end the Bureau conducts research and provides central national services in four broad program areas. These are: (1) basic measurements and standards, (2) materials measurements and standards, (3) technological measurements and standards, and (4) transfer of technology.

The Bureau comprises the Institute for Basic St andards, the Institute for Materials Research, the Institute for Applied Technology, the Center for Radiation Research, the Center for Computer Sciences and Technology, and the Office for Information Programs.

THE INSTITUTE FOR BASIC STANDARDS provides the central basis within the United States of a complete and consistent system of physical measurement; coordinates that system with measurement systems of other nations; and furnishes essential services leading to accurate and uniform physical measurements throughout the Nation's scientific community, industry, and commerce. The Institute consists of an Office of Measurement Services and the following technical divisions:

Applied Mathematics-Electricity-Metrology-Mechanics-Heat-Atomic and Molecular Physics-Radio Physics —-Radio Engineering "-Time and Frequency - - Astrophysics "-Cryogenics."

THE INSTITUTE FOR MATERIALS RESEARCH conducts materials research leading to improved methods of measurement standards, and data on the properties of well-characterized materials needed by industry, commerce, educational institutions, and Government; develops, produces, and distributes standard reference materials; relates the physical and chemical properties of materials to thcir behavior and their interaction with their environments; and provides advisory and research services to other Government agencies. The Institute consists of an Office of Standard Reference Materials and the following divisions:

Analytical Chemistry-Polymers-Metallurgy-Inorganic Materials-Physical Chemistry. THE INSTITUTE FOR APPLIED TECHNOLOGY provides technical services to promote the use of available technology and to facilitate technological innovation in industry and Government; cooperates with public and private organizations in the development of technological standards, and tcst methodologies; and provides advisory and research services for Federal, state, and local government agencies. The Institute consists of the following technical divisions and offices:

Engineering Standards-Weights and Measures - Invention and Innovation - Vehicle Systems Research-Product Evaluation-Building Research-Instrument Shops-Measurement Engineering-Electronic Technology-Technical Analyșis.

THE CENTER FOR RADIATION RESEARCH engages in research, measurement, and application of radiation to the solution of Bureau mission problems and the problems of other agencies and institutions. The Center consists of the following divisions:

Reactor Radiation-Linac Radiation-Nuclear Radiation-Applied Radiation.

THE CENTER FOR COMPUTER SCIENCES AND TECHNOLOGY conducts research and provides technical services designed to aid Government agencies in the selection, acquisition, and effective use of automatic data processing equipment; and serves as the principal focus for the development of Federal standards for automatic data processing equipment, techniques, and computer languages. The Center consists of the following offices and divisions:

Information Processing Standards-Computer Information - Computer Services - Systems Development-Information Processing Technology.

THE OFFICE FOR INFORMATION PROGRAMS promotes optimum dissemination and accessibility of scientific information generated within NBS and other agencies of the Federal Government; promotes the development of the National Standard Reference Data System and a system of information analysis centers dealing with the broader aspects of the National Measurement Systcm, and provides appropriate services to ensure that the NBS staff has optimum accessibility to the scientific information of the world. The Office consists of the following organizational units:

Office of Standard Reference Data-Clearinghouse for Federal Srientific and Technical Information "-Office of Technical Information and Publications-Library-Office of Public Information-Office of International Relations.

Headquarters and Laboratories at Gaithersburg. Maryland, unless otherwise noted; mailing address Washington, D.C. 20234.
Located at Boulder. Colorado 80302 .

s Located at 5285 Port Royal Road, Springfield, Virginia 22151. 


\title{
NBS TECHNICAL NOTE 521
}

\author{
ISSUED AUGUST 1970
}

Nat. Bur. Stand. (U.S.), Tech. Note 521, 17 pages (Aug. 1970)

CODEN: NBTNA

\section{Present State of the Classical Theory of Quantitative Electron Probe Microanalysis}

\author{
Kurt F. J. Heinrich \\ Spectrochemical Analysis Section \\ Analytical Chemistry Division \\ Institute for Basic Standards \\ National Bureau of Standards \\ Washington, D.C. 20234
}

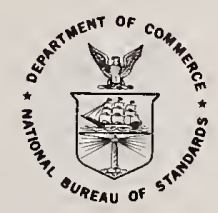

NBS Technical Notes are designed to supplement the Bureau's regular publications program. They provide a means for making available scientific data that are of transient or limited interest. Technical Notes may be listed or referred to in the open literature.

For sale by the Superintendent of Documents, U.S. Government Printing Office, Washington, D.C. 20402 (Order by SD Catalog No. C 13.46: 521). Price 30 cents 


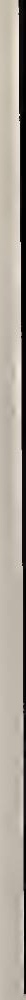


PRESENT STATE OF THE CLASSICAL THEORY OF

QUANTITATIVE ELECTRON PROBE MICROANALYSIS*

Kurt F. J. Heinrich

Analytical Chemistry Division

Institute for Materials Research

National Bureau of Standards

Washington, D。C. 20234

Although the foundations for a procedure of data reduction in quantitative electron probe analysis have not been changed for several years, there has been progress in the choice of expressions, parameters, and constants. A brief account of recommended expressions and procedures is given. Reference is made to the Standard Reference Materials of $\mathrm{Au}-\mathrm{Ag}$ and $\mathrm{Au}-\mathrm{Cu}$ alloys issued for electron probe microanalysis. These are especially useful for investigating the application of correction procedures.

Key words: corrections; electron probe microanalysis; quantitative analysis; $\mathrm{x}$-ray spectroscopy .

\section{INTRODUCTION}

In his doctoral thesis, published in 1951 [1], Castaing laid the groundwork for a theory of quantitative electron probe microanalysis. He pointed out that the intensity of characteristic primary radiation generated in multi-element specimens is approximately proportional to the mass fraction of the emitting element. He therefore proposed that the corrections which need to be applied to measured $x$-ray intensity ratios to obtain mass fractions ("concentrations") were as follows:

This paper is to appear in Mikrochim. Acta, in German, as part of the proceedings of a meeting on electron probe microanalysis and metallography, held in Vienna, (Technische Hochschule, Wien), October 22-25, 1969. 
1. An absorption correction, which takes into account the absorption of $x$-rays emerging from the specimen, and

2. A fluorescence correction which cancels the effects of indirect $x$-ray generation.

Castaing also suggested that for accurate analysis the proportionality between concentration and intensity of emission may have to be considered an insufficient approximation. Hence, he proposed a form of atomic number correction to correlate more accurately the mass fraction with the measured intensity of $\mathrm{x}$-ray emission.

This "classical" scheme of data reduction has essentially remained the commonly used approach to quantitative analysis. It has been described in many publications, including the National Bureau of Standards Special Publication 298 (1968) [2], which contains several references used in this paper. In the recent past there has been considerable discussion of the choice of parameters and constants to be employed within the framework of this procedure. The problem remains if, instead of the classical procedure, a Monte-Carlo method or a transport equation procedure is used to calculate the mass-fractions of the elements being measured.

It is the purpose of the present publication to give an account of the specific choices of parameters and constants which are available at present for the computation of corrections for quantitative electron probe microanalysis. For a general description of the correction procedures, as well as for a detailed discussion of the origin of these expressions, the reader is referred to the cited literature. 
ATOMIC NUMBER CORRECTION

Thanks to the work of many investigators [e.g. 2-6] the processes resulting in primary $x$-ray emission are now quite well understood. The number of ionizations produced by a single electron coming to rest within the target can be written as follows ${ }^{*}$;

$$
\mathrm{n}_{\mathrm{A}}=\mathrm{N}_{\mathrm{Av}} \cdot \rho \cdot \frac{\mathrm{C}_{\mathrm{A}}}{\mathrm{A}} \int_{\mathrm{E}_{\mathrm{o}}}^{\mathrm{O}} \frac{\mathrm{Q}}{-\mathrm{dE} / \mathrm{dx}} \mathrm{dE}
$$

For the ionization cross-section, Q, and the stopping power, $-d E / d(\rho x)$, we can substitute in the above equation the expressions proposed by Bethe et al. $[7,8]$ :

$$
\begin{aligned}
& \mathrm{Q}=\mathrm{b} \cdot \pi \mathrm{e}^{4} \cdot \mathrm{z}_{\ell} \cdot \frac{\ln \mathrm{U}}{\mathrm{U}} \cdot \mathrm{E}^{-2} \\
& \mathrm{~S} \equiv-\frac{1}{\rho} \cdot \frac{\mathrm{dE}}{\mathrm{dx}}=2 \pi \mathrm{e}^{4} \cdot \mathrm{N}_{\mathrm{Av}} \cdot \frac{\mathrm{Z}}{\mathrm{A}} \cdot \frac{1}{\mathrm{E}} \ln \left(\frac{\alpha \mathrm{E}}{J}\right)
\end{aligned}
$$

The values of some parameters of these equations are, however, poorly known. Hénoc has concluded from the study of experimental results on the ionization cross section that the value $\mathrm{b}=0.76$, can be considered valid for all levels of ionization [9]. The value of the coefficient $\alpha$ in equation (3) was frequently considered to be equal to two. However, according to Nelms [10], for electrons the value $\alpha=1.166$ should be used.

There is some controversy concerning the best expression for the mean ionization potential, $\mathrm{J}$. The value ( $\mathrm{J}=11 \cdot 5 \mathrm{Z}$ ). used frequently in the past, is certainly inaccurate. We use at present an expression obtained by Berger and Seltzer [11], who averaged a large number of experimental observations by several authors:

$$
J=9.76 Z+58.5 Z^{-0.19}
$$

*A list of symbols used is appended. 
Another expression for $J$ has been proposed by Duncumb et al. [12]:

$$
\mathrm{J} / \mathrm{Z}=14.0[1-\exp (-0.1 \mathrm{Z})]+75.5 / \mathrm{Z}^{\mathrm{Z} / 7.5}-\mathrm{Z} /(100+\mathrm{Z})
$$

This equation has been derived empirically to optimize the results of a large number of electron probe analyses of specimens of known composition. We withold judgment on the best choice of expression for $J$, pending further investigations.

In order to obtain an algebraic expression for ionization within a multi-element target, we introduce the variables $\mathrm{M}$ and $V$, defined by the following equations:

$$
M=\sum_{i} C_{i} \frac{Z_{i}}{A_{i}} ; \quad V=\exp \left[\frac{1}{M} \sum_{i} C_{i} \frac{Z_{i}}{A_{i}} \ln \left(\frac{\alpha E}{J_{i}}\right)\right]
$$

As shown by springer [13], if one introduces equations (2), (3), and (6), the integration of equation (1) yields the expression

$$
\mathrm{n}_{\mathrm{A}}=\frac{1}{2} \frac{\mathrm{C}_{\mathrm{A}}}{\mathrm{A}} \mathrm{z}_{\mathrm{l}} \mathrm{b} \frac{1}{\mathrm{M}}\left\{\mathrm{U}_{\mathrm{o}}-1-\frac{\ln \mathrm{V}}{\mathrm{V}}\left[\mathrm{EI}\left(\ln \left(\mathrm{U}_{\mathrm{o}} \mathrm{V}\right)\right)-\mathrm{EI}(\ln \mathrm{V})\right]\right\}
$$

in which EI is the exponential integral:

$$
\mathrm{EI}(\mathrm{x})=\text { const. }+\ln \mathrm{x}+\sum_{s=1}^{s=\infty} \frac{\mathrm{x}^{\mathrm{s}}}{\mathrm{s} \cdot \mathrm{s} !}
$$

Expression (7) is used in an extensive program for data processing in quantitative electron probe microanalysis, called cor, recently developed by Hénoc and Heinrich at the National Bureau of Standards [14].

A further correction is necessary to take account of the effects of electron backscattering. A fraction of the impinging electrons is reemitted with energies sufficient to excite $x$-rays. This reduces the generated $x$-ray intensity by a fac- 
tor $\mathrm{R}$ (backscatter effect), which decreases rapidly with increasing atomic number. The average number of ionizations per impinging electron is thus $n_{A} R$. We believe that the most reliable expression for the factor $R$ is that proposed by Duncumb [15]:

$$
\begin{aligned}
R & =1.0000+ \\
& +\left(-.581+2.162 W-5.137 W^{2}+9.213 W^{3}-8.619 W^{4}+2.962 W^{5}\right) \times 10^{-2} Z+ \\
& +\left(-1.609-8.298 W_{+} 28.791 W^{2}-47.744 W^{3}+46.540 W^{4}-17.676 W^{5}\right) \times 10^{-4} Z^{2}+ \\
& +\left(5.400+19.184 W-75.733 W^{2}+120.050 W^{3}-110.700 W^{4}+41.792 W^{5}\right) \times 10^{-6} Z^{3}+ \\
& +\left(-5.725-21.645 W_{+} 88.128 W^{2}-136.060 W^{3}+117.750 W^{4}-42.445 W^{5}\right) \times 10^{-8} Z^{4}+ \\
& +\left(2.095+8.947 W-36.510 W^{2}+55.694 W^{3}-46.079 W^{4}+15.851 W^{5}\right) \times 10^{-10} Z^{5}
\end{aligned}
$$

where $\mathrm{W}=1 / \mathrm{U}_{0}=\mathrm{E}_{0} / \mathrm{E}_{\mathrm{K}}$. This expression agrees well with the experimental measurements of the factor $R$ by Dérian [16]. The number of photons of the $\mathrm{x}$-ray line $\mathrm{n}$, generated by ionization of the electron shell $\mathrm{m}$, is obtained by multiplying the number of ionizations, $n_{A} R$, with the fluorescence yield, $\omega_{m}$, and with the ratio of the intensity of the line of interest to the intensity of all lines originating from this shell (weight of the line, $\mathrm{p}_{\mathrm{mn}}$ ):

$$
\mathrm{I}_{\mathrm{Ap}}^{\prime}=\mathrm{n}_{\mathrm{A}} \cdot \mathrm{R} \cdot \omega_{\mathrm{m}} \cdot \mathrm{p}_{\mathrm{mn}}
$$

\section{THE ATTENUATION OF PRIMARY RADIATION}

The attenuation of primary radiation on emergence from the specimen can be calculated using an equation proposed by Philibert [17]

$$
1 / \mathrm{f}(\chi)=\left(1+\frac{\chi}{\sigma}\right)\left(1+\frac{\mathrm{h}}{1+\mathrm{h}} \cdot \frac{\chi}{\sigma}\right) ; \mathrm{h}=1.2 \frac{\mathrm{A}}{\mathrm{Z}^{2}} ;
$$

The factor $f(x)$ is the ratio between attenuated and unattenuated primary radiation: $F(x)=I_{p} / I_{p}^{\prime}$. Expressions for the coefficient $\sigma$, which depends on the electron energy, were pro- 
posed by Duncumb and Shields [18] and by Heinrich [19]. We presently use the following equation:

$$
\sigma=\frac{4.5 \times 10^{5}}{\mathrm{E}_{\mathrm{o}}^{1.65}-\mathrm{E}_{\mathrm{k}}^{1.65}}
$$

We have not evaluated an alternative equation for the absorption correction, by Wittry and Andersen [20].

The attenuation of primary radiation is large when $x$-rays of low photon energy are measured. It is important to note, however, that the magnitude of this effect, and hence, the uncertainty of its computation, depends upon experimental conditions under our control. Primary absorption can be minimized by working at low electron energies and using high $\mathrm{x}$-ray emergence angles; and these conditions are desirable when soft $\mathrm{x}$-rays are measured. It should be added that further experiments on the depth distribution of primary $x$-rays should be encouraged. The uncertainties in the absorption correction have been analyzed by Yakowitz and Heinrich [21] who suggested that the experimental conditions should be adjusted, wherever possible, to maintain the value of $f(x)$ above 0.8 .

SECONDARY RADIATION EXCITED BY CHARACTERISTIC LINES

The effects of secondary radiation excited by characteristic lines are usually treated according to the equation proposed by Castaing [1]:

$$
r_{f} \equiv \frac{I_{f A}}{I_{p A}}=C_{B} \cdot \frac{I_{p A}^{\prime}}{I_{p A}^{\prime}} \cdot \frac{r_{A}-1}{r_{A}} \cdot \frac{\omega_{B}}{2} \frac{\mu(A, B K \alpha)}{\mu\left(A B, B K_{\alpha}\right)} \cdot \frac{A}{B}\left[\frac{\ln (1+u)}{u}+\frac{\ln (1+v)}{v}\right]
$$

In this equation, $r_{f}$ is the ratio of the attenuated fluorescent radiation to the attenuated primary radiation of the element which is being determined. $I_{\mathrm{pB}}^{\prime} / I_{\mathrm{pA}}^{\prime}$ is the ratio of the gener- 
ated (not attenuated) primary emissions of the exciting and the excited lines as obtained from pure elements. Castaing proposed to approximate this ratio by the ratio of the absorption edge wavelengths of these elements, while Reed [22] replaced it by the expression $\left[\left(\mathrm{U}_{\mathrm{B}}-1\right) /\left(\mathrm{U}_{\mathrm{A}}-1\right)\right]^{1.67}$ in which $\mathrm{U}_{\mathrm{A}}$ and $\mathrm{U}_{\mathrm{B}}$ are the corresponding overvoltage ratios.

This procedure is amenable to several improvements which were incorporated in the program COR. In this program, the ratio $I_{B} / I_{A}$ is fully calculated, using equation (10) for primary intensities, just as in the atomic number correction. This simplifies the calculation of fluorescence of $\mathrm{K}$ lines by L lines and vice versa, as well as the calculation of fluoresence of $K \alpha$ lines by $K \beta$ lines, which is performed separately. As pointed out by Criss [23], the exponential approximation to primary distribution in depth of $x$-ray emission, used by Castaing to calculate the term $v$ in equation (13), can be replaced by a more accurate model. We use in COR the model contained in Philibert's calculation for the function $f(x)$ [17]. With the computer facilities presently available to most analysts, this more rigorous approach is possible without an excessive increase in the cost of computation.

\section{SECONDARY RADIATION EXCITED BY THE CONTINUUM}

Hénoc has described a method for calculating the effects of secondary radiation excited by the continuum [24]. In order to perform the formal integration of the expressions contained in his procedure, he had to make the simplifying assumption that between absorption edges the mass attenuation coefficients vary with the cube of wavelength. However, the wavelength dependence of mass attenuation coefficients is always less than cubic [25]. This has been taken into account in the modification of Hénoc's original method incorporated 
in the program COR. The formal integration is replaced by a numerical integration, using the parameters for attenuation coefficients published in reference [25].

The main practical difficulty in performing the correction for fluorescence excited by the continuum is that the position of the absorption edges of all elements contained in specimen and standard must be taken into account. Each wavelength range between adjacent absorption edges must be calculated separately. Therefore, the procedure is lengthy, and in machine computation it requires extensive data input. Errors in the input occur frequently and may escape detection, since it is difficult to acquire an intuitive feeling for the magnitude of this correction.

In the program COR the relations between lines and absorption edges are inspected by the computer which selects the wavelength ranges for the integration. These decisions are made and the computer completes the calculation without active intervention of the operator. In the same process, the computer also determines which operations must be performed for calculating secondary excitation by characteristic lines. This enormously simplifies the execution of the fluorescence corrections, and renders unnecessary further attempts to simplify them, as advocated by springer [26].

\section{THE ITERATIVE PROCESS}

We will now discuss how the individual corrections are combined in calculating the composition of the specimen.

The usual form employs multiplicative correction factors:

$$
C^{*}=k \cdot k_{Z}^{*} \cdot k_{A}^{*} \cdot k_{F}^{*}
$$


This procedure is based on the concept that ideally the method should yield a linear correction curve. The multiplicative factors correct for deviations from the ideal model. However, the values of the correction factors depend on the composition of the specimen, which is unknown. The problem is traditionally resolved by using an estimate of composition to calculate the correction factors, and using the resulting mass fractions as a new estimate of composition and iterating until convergence of results is obtained.

As stated by Criss [23], the formulation of the correction by multiplicative factors unnecessarily complicates the structure of the correction equations, and obscures the underlying physical events. Moreover, the iteration frequently fails to converge, as observed by Reed [27]. For these reasons, the program COR uses a different iterative concept, first proposed by Criss and Birks [28], and somewhat modified by Hénoc and Heinrich.

Each iteration contains two steps. In the first step, we establish an estimate of the specimen composition and calculate the intensity ratios to be expected for each element, according the theory. The intensity ratios are obtained by the simple relation

$$
\mathrm{K}=\frac{\mathrm{I}^{*}}{\mathrm{I}}=\frac{\mathrm{I}_{\mathrm{p}}^{*}+\mathrm{I}_{\mathrm{c}}^{*}+\Sigma \mathrm{I}_{\mathrm{f}}^{*}}{\mathrm{I}_{\mathrm{p}}+\mathrm{I}_{\mathrm{c}}+\Sigma \mathrm{I}_{\mathrm{f}}}
$$

The correction procedures previously discussed are used to calculate the absolute intensities (in photons per electron) due to direct and indirect excitation. As a first estimate of the specimen composition we assume that the weight fractions of the elements are proportional to the experimentally obtained $x-r a y$ intensity ratios. This estimate, as well as the subsequent estimates is normalized so as to render the sum of mass fractions equal to unity. Thus, in each iteration, we calculate 
the signal intensities to be expected from a theoretically possible composition.

Since equation (15) does not yield an explicit term for mass fractions, we must use another relation to obtain, in the second step of each iteration, a new estimate of composition. We use for this purpose a hyperbolic approximation to the analytical calibration curve for each element:

$$
\frac{1-\mathrm{k}}{\mathrm{k}}=\mathrm{a} \frac{1-\mathrm{C}}{\mathrm{C}}
$$

Ziebold and Ogilvie observed that the analytical curves in electron probe microanalysis are indeed approximately hyperbolic [29]. On the plot of intensity ratio versus mass fraction for each element, the hyperbola can be defined by three points $(0,0),(1,1)$, and $(C, k)$, where $C$ and $k$ are the estimate of mass fraction used in the iteration, and of the intensity ratio calculated for it. Our next estimate for the mass fraction, $\mathrm{C}_{\mathrm{m}}$, corresponding to the observed intensity ratio, $\mathrm{k}_{\mathrm{m}}$, can thus be calculated by the equation

$$
C_{m}=\frac{k_{m} \cdot C(1-k)}{k_{m}(C-k)+k(1-C)}
$$

Contrary to the procedure suggested by Criss, we do not normalize the observed intensity ratios $k$ in equation (16), or the final results after convergence. Thus, if the presence of an element has been overlooked, or if there are experimental errors or failures of the correction procedures, this will become apparent since the calculated mass fractions fail to sum to unity。

This iteration procedure has been extensively tested. We have never observed failure to converge. In fact, the convergence is always rapid, as is to be expected in view of the good fit of the hyperbolic model observed by Ziebold and Ogilvie. 
The program COR can also compute results of analysis with use of multi-element standards; furthermore it can determine one element by difference or several unmeasured elements on the basis of stoichiometric relations.

\section{STANDARD REFERENCE MATERIALS}

In spite of the progress made in recent years, there are still uncertainties in several aspects of the correction procedures. I believe that the availability of reliable standard reference materials will be instrumental in pointing out the areas in which further investigation is most needed. For this reason, the National Bureau of Standards has devoted considerable effort to preparing and characterizing materials specially selected for electron probe microanalysis [30]. Recently, NBS certified and issued an alloy of nominal composition $0.8 \mathrm{~W}$, 0.2 Mo, a series of binary alloys in the Au-Ag system, in nominal steps of 0.2 (20 weight percent), and a similar series of alloys in the system $\mathrm{Au}-\mathrm{Cu}$. All these alloys were carefully analyzed chemically by several laboratories, and painstakingly investigated for homogeneity. They should be particularly useful in testing the atomic number correction. Extension of the studies of oxydic systems is presently in progress. 
[1] Castaing, R., Doctoral Thesis, Univ. Paris (1951).

[2] Green, M., Doctoral Thesis, Univ. Cambridge, England $(1962)$.

[3] Philibert, J. and Tixier, R., Nat. Bur. Stand. (U.S.), Spec. Publ。298, 13-33(1968).

[4] Brown, D. B., Nat. Bur. Stand. (U.S.), Spec. Publ. 298, $63-79(1968)$.

[5] Poole, D. M., Nat. Bur. Stand. (U.S.), Spec. Publ. 298, 93-131 (1968).

[6] Duncumb, P. and Reed, S. J. B., Nat. Bur. Stand. (U.S.), Spec. Publ. 298, 133-154 (1968).

[7] Bethe, H. A., Ann. Phys. Lpz . 5, 325-400 (1930).

[8] Bethe, H. A., Rose M. E. and Smith, L. P., Proc. Am. Phil. Soc. 78, 573-585 (1938).

[9] Hénoc, J., private communication.

[10] Nelms, A. T., Nat. Bur. Stand. (U.S.), Circ 577 (1956).

[11] Berger, M. J. and Seltzer, S. M., Nat. Acad. Sci., Nat. Res. Council Publ. 1133, 205, Washington, D. C., (1964).

[12] Duncumb, P., Shields-Mason, P. K. and da Casa, C., Proc. Fifth International Congress on X-ray Optics and Microanalysis, Springer-Verlag, Berlin, 146-150 (1969).

[13] Springer, G. and Miner, N. J. B., Mh., 1967, 304-317

[14] Hênoc, J. and Heinrich, K. F. J., to be published.

[15] Duncumb, P., private communication.

[16] Dérian and Castaing, $R$, Optique des rayons $X$ et microanalyse, Castaing, Deschamps, Philibert, editors, 193-199, Paris, Herman (1966).

[17] Philibert, Proc. Third International Congress on X-ray Optics and X-ray Microanalysis, Academic Press, New York, 379-392 (1963). 
[18] Duncumb, P. and Shields, P. K. Shields, The Electron Microprobe, McKinley, Heinrich, Wittry, editors, Plennum Press, New York, 40-55 (1968).

[20] Andersen, C. A. and Wittry, D. B., Brit. J. Appl. Phys., Ser. 2, I, 529-540 (1968).

[21] Yakowitz, H. and Heinrich, K. F. J., Mikrochim. Acta 1968, $182-200$ 。

[22] Reed, S. J. B., Brit. J. Appl. Phys. 16, 913-926 (1965).

[23] Criss, J. W., Nat. Bur. Stand. (U.S.), Spec. Publ. 298, $52-62(1968)$.

[24] Hénoc, J., Nat. Bur. Stand. (U.S.), Spec. Publ. 298, $197-214$ (1968).

[25] Heinrich, K. F. J., The Electron Microprobe, McKinley, Heinrich, Wittry, editors, John Wiley, New York, 296-377 (1966).

[26] Springer, G., N. Jb. Miner. Abh. 106, 241-256 (1967).

[27] Reed, S. J. B. and Mason, P. K., Paper presented at the Second National Conference on Electron Microprobe Analysis, June 14-16, 1967, Boston, Massachusetts.

[28] Criss, J. W. and Birks, L. S., The Electron Microprobe, McKinley, Heinrich, Wittry, editors, John Wiley, New York, 217-236 (1966).

[29] Ziebold, T. O. and Ogilvie, R. E., The Electron Microprobe, McKinley, Heinrich, Wittry, editors, John Wiley, New York, 378-389 (1966).

[30] NBS Certificates of Analysis, Standard Reference Materials 480 (1968), 481, 482 (1969). 
$A, B$

C

E

E

$E_{k}$

I

$I^{\prime}$

$J$

M

$\mathrm{N}_{\mathrm{Av}}$

Q

$\mathrm{R}$

S

U

$\mathrm{U}_{\mathrm{O}}$

$\mathrm{V}$

W

Z

a

$\mathrm{b}$

c

e

atomic weights of elements A, B

mass fraction ("concentration")

kinetic energy of the electron

initial kinetic energy of the electron, operating voltage

excitation potential of line $k$

attenuated (emergent) intensity of radiation

intensity of generated radiation, before attenuation

mean ionization potential

variable used for stopping power calculation (eq. $6-7$ )

Avogadro's number

ionization cross-section

correction factor for electron backscattering

stopping power

$=\mathrm{E} / \mathrm{E}_{\mathrm{k}}$

$=E_{0} / E_{k}$

variable used for stopping power calculation (eq. $6-7$ )

$=1 / \mathrm{U}_{0}$

atomic number

constant in the hyperbolic approximation

constant in the calculation of the ionization

cross-section

constant in the calculation of $\sigma$

charge of electron 
$f(x) \quad$ correction factor for absorption of primary radiation

h

$=1.2\left(\mathrm{~A} / \mathrm{Z}^{2}\right)$ in Philibert's equation. For multielement targets, $h=\sum_{i} C_{i} A_{i} / Z_{i}^{2}$

EI exponential integral

In natural logarithm

$\mathrm{n}_{\mathrm{A}} \quad$ number of ionizations produced by one electron which comes to rest within the specimen

$\mathrm{p}_{\mathrm{mn}}$

relative frequency of the line $n$, generated on ionization of the shell $\mathrm{m}$, with respect to generation of all lines originating from shell $\mathrm{m}$

r absorption edge jump of the absorption coefficient $r_{f}$ intensity of emerging fluorescent radiation, relative to emerging primary radiation of the same line

S

tally in the exponential integral

$k$

relative intensity of emergent radiation

$k_{Z}, k_{A}, k_{F}$

correction factors for atomic number, absorption, and fluorescence effects

$\mathrm{u}, \mathrm{v}$

auxiliary variables for attenuation of fluorescent radiation

$\alpha$

constant in Bethe's equation for energy loss of electrons

$\theta$

emergence angle of measured $x$-rays

$\mu$

$\mathrm{x}$-ray mass attenuation coefficient

$\mu(A B, A K \alpha)$ mass attenuation coefficient of specimen containing elements $A$ and $B$, for $K \alpha$ radiation of element $A$

$\rho$ density of specimen

$\sigma$ coefficient for electron energy effect in Philibert's equation

$x$

$\omega$

$=\mu \operatorname{cosec} \theta$

= fluorescence yield 
Subscripts and superscripts:
A, B
elements A, B
i
tally in integration
1
electron shell I
*
composition dependent 
PERIODICALS

JOURNAL OF RESEARCH reports National Bureau of Standards research and development in physics, mathematics, chemistry, and engineering. Comprehensive scientific papers give complete details of the work, including laboratory data, experimental procedures, and theoretical and mathematical analyses. Illustrated with photographs, drawings, and charts.

\section{Published in three sections, available separately:}

\section{Physies and Chemistry}

Papers of interest primarily to scientists working in these fields. This section covers a broad range of physical and chemical research, with major emphasis on standards of physical measurement, fundamental constants, and properties of matter. Issued six times a year. Annual subscription: Domestic, $\$ 9.50$; foreign, $\$ 11.75^{*}$.

\section{Mathematical Sciences}

Studies and compilations designed mainly for the mathematician and theoretical physicist. Topics in mathematical statistics, theory of experiment design, numerical analysis, theoretical physics and chemistry, logical design and programming of computers and computer systems. Short numerical tables. Issued quarterly. Annual subscription: Domestic, $\$ 5.00$; foreign, $\$ 6.25 *$.

\section{Engineering and Instrumentation}

Reporting results of interest chiefly to the engineer and the applied scientist. This section includes many of the new developments in instrumentation resulting from the Bureau's work in physical measurement, data processing, and development of test methods. It will also cover some of the work in acoustics, applied mechanics, building research, and cryogenic engineering. Issued quarterly. Annual subscription: Domestic, $\$ 5.00$; foreign, $\$ 6.25^{*}$.

\section{TECHNICAL NEWS BULLETIN}

The best single source of information concerning the Bureau's research, developmental, cooperative and publication activities, this monthly publication is designed for the industry-oriented individual whose daily work involves intimate contact with science and technology-for engineers, chemists, physicists, research managers, product-development managers, and company executives. Annual subscription: Domestic, $\$ 3.00$; foreign, $\$ 4.00^{*}$.

- Difference in price is due to extra cost of foreign mailing.

\section{NONPERIODICALS}

Applied Mathematics Series. Mathematical tables, manuals, and studies.

Building Science Series. Research results, test methods, and performance criteria of building materials, components, systems, and structures.

Handbooks. Recommended codes of engineering and industrial practice (including safety codes) developed in cooperation with interested industries, professional organizations, and regulatory bodies.

Special Publications. Proceedings of NBS conferences, bibliographies, annual reports, wall charts, pamphlets, etc.

Monographs. Major contributions to the technical literature on various subjects related to the Bureau's scientific and technical activities.

National Standard Reference Data Series. NSRDS provides quantitive data on the physical and chemical properties of materials, compiled from the world's literature and critically evaluated.

Product Standards. Provide requirements for sizes, types, quality and methods for testing various industrial products. These standards are developed cooperatively with interested Government and industry groups and provide the basis for common understanding of product characteristics for both buyers and sellers. Their use is voluntary.

Technical Notes. This series consists of communications and reports (covering both other agency and NBS-sponsored work) of limited or transitory interest.

Federal Information Processing Standards Publications. This series is the official publication within the Federal Government for information on standards adopted and promulgated under the Public Law 89-306, and Bureau of the Budget Circular A-86 entitled, Standardization of Data Elements and Codes in Data Systems.

\section{CLEARINGHOUSE}

The Clearinghouse for Federal Scientific and Technical Information, operated by NBS, supplies unclassified information related to Government-generated science and technology in defense, space, atomic energy, and other national programs. For further information on Clearinghouse services, write:

Clearinghouse

U.S. Department of Commerce

Springfield, Virginia 22151 
U.S. DEPARTMENT OF COMMERCE

WASHINGTON, D.C. 20230

OFFICIAL BUSINESS

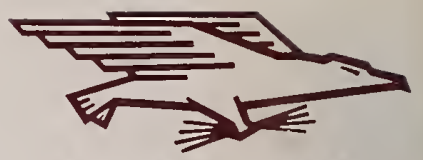

POSTAGE AND FEES PAID

U.S. DEPARTMENT OF COMMERCE 